\title{
The influence of service recovery on perceived justice under different involvement level-an evidence of retail industry
}

\author{
Hong-Sheng Chang \\ De-Lin Institute of Technology \\ E-Mail: hschang@dlit.edu.tw \\ Ju-Chun Lee \\ De-Lin Institute of Technology \\ E-Mail: zoe@dlit.edu.tw \\ Chien-Ming Tseng \\ Ming-Chuan University \\ Central Taiwan University of Science and Technology \\ E-Mail: bryan@ctust.edu.tw
}

\begin{abstract}
The purpose of this work is to elucidate how service recovery and perceived justice are related, and explores the modulation effect of involvement level and subculture in this relationship. Samples were collected using the questionnaire, which had been assessed the quality of our measurement efforts by investigating reliability and validity. Under high involvement level, perceived justice is found to be affected mainly by atonement and empowerment, whereas communication, feedback, explanation and tangibles influence perceived justice under low involvement level. Moreover, under city subculture, perceived justice is found to be affected mainly by communication, feedback, explanation and empowerment. Furthermore, under country subculture, perceived justice is found to be affected mainly by atonement and tangibles. Finally, for three dimensions of perceived justice, under high involvement level, distributive justice is found to be affected by service recovery, whereas service recovery influence interactive justice under low involvement. Under city subculture, processing justice is found to be affected by service recovery, whereas service recovery influence distributive justice. For future
\end{abstract}


research, other modulation effect of service recovery may influence perception of perceived justice should be discussed. In practice, hotel managers can hone the relevant variables to raise the effect of service recovery on perceived justice. Finally, this study provides a new shape of the "structural" relationships among involvement, subculture and three perceived justices.

Keywords: Service Recovery, Perceived Justice, Involvement, Subculture

\section{INTROUDUCTION}

Service recovery studies both in Taiwan and overseas tend to focus on perceived justice effects on customer satisfaction. Most studies indicate that enterprises taking recovery measures to compensate for service failures can double the satisfaction of their customers by restoring favorable impressions of both products and service. As rising national consumption increases market competition, marketing strategies for product promotion should focus on consumers. For instance, to meet the needs of consumers, socalled involvement and subculture must be clearly understood. The influence of service recovery on perceived justice can be controlled by the modulating effect of involvement level and subculture. Therefore, when the modulating effect of involvement level and subculture is controlled, enterprises grasp the best timing of service recovery.

Service failures may upset or anger customers, but failure to immediately and effectively address service failures is sure to arouse dissatisfaction or complaints. Core service failure is exactly what customers complain about the most (Hoffman, Kelley \& Rotalsky, 1995). Still worse, poor core service is the main cause of lost customer loyalty. The worse the service failure was, the lower the customer satisfaction (Hoffman, Kelley \& Rotalsky, 1995). Likewise, during service, the fastness of service failure occurrence lowers customer satisfaction. The reason for complaint is that customers have never experienced satisfactory service (Boulding, Kalra \& Zeithaml, 1993). When customers realize the cause of a service failure, especially when they have sufficient cause to blame the enterprise, their dissatisfaction will increase due to anticipation of further service failure. Furthermore, if customers feel the failure is avoidable by enterprises, their dissatisfaction is much worse than if the failure occurred through the fault of the enterprise (Bitner, Booms \& Tetreault, 1990).

Liao (2007) integrates justice and customer service literatures, this research 
examines the role of customer service employees' behaviors of handling customer complaints, or service recovery performance (SRP), in conveying a just image of service organizations and achieving desirable customer outcomes. Kau \& Loh (2006) show that dissatisfied complainants would exhibit a lower level of trust and were more likely to engage in negative word-of-mouth behavior compared with those who were dissatisfied initially but chose not to complain. The findings in this paper confirmed the importance of perceived justice in service recovery. Satisfaction with service recovery also leads to a higher level of trust, positive word-of-mouth behavior and, to a lesser extent, the level of loyalty.

In business enterprises, especially in the service industry, occurrence of service failure is unavoidable, because service includes many features, such as immaterial, inalienable, diverse, heterogeneous, fugacious, and effect ambiguous. Therefore, in the process of service transmission, one impossible achieves one hundred percent satisfaction (Fisk, Brown, \& Bitner, 1995). In this study, effective service recovery not only wins customers back, but increases their loyalty and is a vital factor influencing customer value (Kelley, Hoffman \& Davis, 1993). Upset customers will feel satisfied with the efforts of the service recovery measures of an enterprise. Service recovery refers to the action taken by enterprises to retain customers following a service failure (Gronroos, 1988). Customers will stay loyal to a company when they are confident their complaints will be addressed (Bowen \& Lawler, 1995). Service failure and failure of service recovery are the primary causes of customer loss. To save customers and minimize the customer loss, enterprises must adopt appropriate service recovery measures, and a successful service recovery strategy is vital.

For example, in the retail industry, a convenience store is defined as a store having an area of 28 to 90 level ground of space; its business hours are longer than other stores; it sells daily necessities and requires self-service; it offers convenience of location, complete goods and timing for customers; it provides parking spaces for five to fifteen cars; its business hours are long or 24 hours all year; the goods sold include at least fifty different food and sundry items, including fast-food, telephone cards and stamps. Importantly, a convenience store aims to build a harmonious relationship with customers, provide friendly service, but mostly self-service. Due to a mistaken classification of retail industry, up to 3 categories and 15 items, service failure and recovery measures should be major concerns of any convenience store (Kelley, Hoffman \& Davis, 1993).

Smith, Bolton \& Wagner (1999) proposed a model of service failure and recovery of 
customer satisfaction by integrating three dimensions of perceived justice to measure the gap between customer expectations and understanding. The findings of their study indicated that service recovery influenced customer satisfaction not directly but rather indirectly through perceived justice. The gap between customer expectancy and understanding indirectly influenced their satisfaction. The Smith study also found that service recovery influenced customer satisfaction based on differences in perceived justice and the gap between customer expectancy and understanding. Although the gap both positively and negatively influences satisfaction, the three aspects of perceived justice could explain up to $60 \%$ of their satisfaction. Further, distribution justice is influenced by atonement of service recovery, processing justice by atonement speed of service recovery, interactive justice by active atonement and apology of the service recovery.

Retailers can be classified in many different ways, such as by ownership, service characteristics, product lines and administration, or by the diversity, convenience, and

prices of product lines (Churchill \& Peter, 1998). However, retailers always emerge with a new business model. Considering this, a classification of retailers might include shop retailers, shopless retailers and retail organizations. Shop retailers include specialty shops, department stores, supermarkets, convenience stores, discount shops, independent low-price shops, large-scale supermarkets and catalogue display stores. New-type retailers include shopping centers or malls, department stores, large-scale wholesalers, supermarkets and convenience stores.

In view of previous studies of retailers, including convenience stores on the life styles and impressions of shops, with fewer studies on service recovery, we start our motivation for studying the practicability of service recovery on retail management, which is now widely applied in both academic and business fields. This study constructs a theoretical model of service recovery on perceived justice and further explores its modulating effect.

\section{THEORY BACKGROUND AND HYPOTHESES}

\section{Service Failure and Recovery}

Service failure occurs when a customer has negative feelings, is dissatisfied or has an unpleasant experience during a service encounter. (Bitner, Boom \& Tetreault, 1990; Bitner, Bernard \& Mohr, 1994). Binter et al. (1990) explored some of the various 
aspects of service failure, fore example: the enterprise is unable to provide the customer with the requested service, the service is not executed according to standard procedure, the service is delayed or the core service falls below the acceptable level of quality. Customers often feel initial disappointment or anger after encountering a service failure. However, this initial reaction can be avoided or minimized if the enterprise can effectively explain the reason for the service failure and implement a service recovery strategy in a timely manner. A study by Hart et al. (1990) suggested that an enterprise wishing to provide consumers with a long-term and consistently satisfactory service and product may be seriously challenged by heterogeneity and non-separation. Service has heterogeneous features because the service provider and the person receiving the service are all related as human beings; service is also non-separated because the consumer must be personally present to receive the service. Because of these two major challenges, an enterprise must develop a range of service recovery strategies.

Service recovery is the action taken to retain customer loyalty by a timely and appropriate response to a customer complaint (Hart, Heskett \& Sasser, 1990). Service recovery encompasses not only the response and action of the service provider to correct the service failure but also the action taken to ameliorate the emotional discontent or even anger of the customer (Gronroos, 1988; Kenney, 1995). Hart et. al (1990) suggested that the purpose of service recovery is to retrieve customers previously lost to service failure and minimize further losses. Service recovery requires positive action to affect customer behavior and can ultimately strengthen customer loyalty to enterprises. Because of heterogeneity and indivisibility, service failure is unavoidable (Tax et al., 1999). Customers expect compensation for losses caused by service failures. Studies indicate that customers believe an enterprise must admit to a fault when it occurs and have a clear service recovery plan to immediately address the service failure (Kelley et al., 1993). According to the Social Exchange and Equity Theory proposed by Smith et al. (1999), service failure and service recovery are a kind of exchange. After the customer suffers losses caused by the service failure, the enterprise must compensate for those losses by providing service recovery measures that offer customer interests.

Schoefer \& Ennew (2005) revealed that perceived justice were predictive of the type of emotion (i.e. positive or negative) elicited. Existing theoretical frameworks focus primarily on cognitive evaluations of perceived justice associated with the complainthandling encounter; the findings of the current study suggest that a cognitive appraisal of perceived justice may also elicit an emotional response, which in turn is expected to 
impact on satisfaction with complaint handling. With a better understanding of the nature and causes of the emotions experienced by customers during service recovery, it should be possible to implement and manage recovery systems that are designed to elicit strongly positive evaluative judgements from consumers. Yim, Gu, Chan \& Tse (2003) also found that consumers form normative recovery expectations distinctly in terms of distributive justice and procedural/interactional justice. These justice-based recovery expectations are also negatively related to recovery disconfirmation as hypothesized. The study also explored potential antecedents to consumer recovery expectations and found that each of the two justice components draws from distinct antecedents. All three tested antecedents - magnitude of service failure, switching cost, and length of the customerorganization relationship - are found to have either a direct or an interactive effect on expectations of distributive justice and procedural/interactional justice.

Eight service recovery strategies can be observed in the restaurant industry: [entertainment, discount, coupons, coordinating by executives, modifying the menu, correcting mistakes, oral apology and no response (Hoffman, Kelley \& Rotalsky, 1995). Furthermore, Boshoff (1999) argued that the manufacturer which suffers the fault should know what the customer reacts in remedying expectation that displays. Conversely, under causing service failure, the customer feels the recovery measure what the manufacturer should offers to them, not what recovery measure will be offered. Boshoff (1999) analyzed the recovery expectations of customers to define the properties of service recovery, and then developed an instrument to measure satisfaction with transactionspecific service recovery (RECOVSAT). According to RECOVSAT, assessed content is divided into the following six dimensions: 1. Attitude and communication skill of employees responsible for recovery; 2. Proper delegation of authority to carry out recovery measures; 3. Proper feedback regarding effectiveness of recovery ; 4. Atonement ; 5. Explanation ; 6. Whether providing with the external and tangible standard such as entity's environment, facility, personnel possess. Due to its proven reliability and validity, this scale is applied in this study.

\section{Perceived justice}

Oliver \& Swan (1989) were the first to model the joint influence of disconfirmation and perceived justice on customer satisfaction, but they addressed only one aspect of perceived justice: the distributive aspect. Their findings indicated that perceived justice is positively related to satisfaction. Goodwin \& Ross (1992) applied a theory of equity to 
explain how service recovery influences customer satisfaction. Their study indicated that customer response to service recovery is determined by two types of perceived justice: processing justice and interactive justice. The Goodwin study presented the justice framework for customer service scenarios in four different service businesses. 1) Distributive justice: the tangible compensation received by a customer after a complaint. 2) Processing justice: the opportunity for the customer to present information and express feelings. 3) Interactive justice: the apology to the customer. We found when tangible compensation is offered, an apology and an opportunity for the consumer to express the problem and feelings increases perception of fairness and satisfaction. When no tangible offering is made, apology and the opportunity for the customer to present information and express feelings has a reduced effect on perception of fairness and satisfaction.

Additionally, Lapidus \& Pinkerton (1995), in a study of service recovery and atonement effects with the justice theory. That study suggested that customers receiving higher compensation have an increased perception of fairness than those receiving lower compensation. Clemmer \& Schneider (1996) proposed that customer assessment of service includes three dimensions: 1. Result: customers receive a profit or loss from the service contact; 2. Process: the service contact is guided by a standard policy or procedure; 3. Interaction: quality of treatment and communication with customers. In a study of the perceived justice aspects of service recovery, Goodwin \& Ross (1992) applied fairness theory to explain the influence of customer satisfaction on service recovery. That study suggested that customer response to service recovery is affected by processing justice and interactive justice. The study found that offering an apology and giving customers the chance to express their feelings improve perceptions of fairness and satisfaction. Regarding [having no essence atonement, offering customers an apology and allowing them an opportunity to express their feelings had a minimal effect on perception of fairness and customer satisfaction. Tax \& Brown (1998) also assessed three dimensions of perceived justice: result, process and interaction.

Chebat \& Slusarczyk (2005) indicate that interactional justice (e.g., courtesy) plays a predominant role, since it impacts both positive and negative emotions and the loyalty behavior. Distributive justice (e.g., compensation offered to the complaining customers) affects the behavior through the symmetrical mediating effects of negative and positive emotions. Procedural justice (i.e., timeliness), which has asymmetric effects on emotions and behavior, plays the role of a "basic requirement". These results are interpreted in terms of Justice Theory and Affect Control Theory (ACT) and in terms of managerial 
implications for services organizations, such as employees' training and complaints' handling. Hoffman \& Kelley (2000) point out that six contingencies are presented that are proposed to influence the relative importance of interactional and distributive justice on consumer-based service recovery evaluations. The six contingencies include: depth of the relationship, proximity of the relationship, duration of the encounter, degree of customization, switching costs, and the criticality of consumption. Relevant research propositions are developed and discussed.

\section{Involvement}

Zaichkowsky (1985) defined involvement as the importance customers feel about something based on their individual demands, values and interests. Krugman (1965) was the first to apply involvement to marketing, using low involvement to analyze the effects of TV commercials. Krugman found that two different reactions occur when consumers are influenced by TV commercials. Low involvement consumers are unlikely to associate with the content of TV commercials; in contrast, high involvement consumers are very likely to associate themselves with the content of TV commercials.

The concept of "perceived risk" was used for the first time to define the involvement of consumers with their purchase. If a purchase is important to a customer, he will endeavor to collect information to reduce the uncertainty of decision making on the purchase (Clark \& Belk, 1978). Involvement has multiple effects on a customer, including changes in risk, attitude, opinion, emotion and cognition. The extent of involvement varies from the process of changing the attitude toward risk. Low involvement consumers change their attitude toward risk more rapidly, and the duration of such a risky attitude is shorter. Therefore, when different brands are advertised, low involvement consumers tend to change brands frequently.

In summary, Zaichkowsky (1985) maintained that involvement is based on personal demands, values and interests which decide the importance of an item. Applied to purchasing behavior, involvement can be divided into product involvement, commercial involvement and purchasing decision involvement. Bloch \& Richins (1983) defined product involvement as the link between products and a persistent or specific situation targeted by customers and defined commercial involvement as the cognitive reaction of customers to commercials or the processing of product information; decision making involvement referred to the concernedness of customers regarding a certain purchasing activity. According to Bloch \& Richins (1983), involvement is defined by cognitive 
reaction and information handling. Based on this, our studies specify involvement as service involvement, meaning the cognitive reaction of customers to service information or service handling. The involvement of customers influences perceived risk, i.e., it affects the relationship between service recovery and perceived risk. Zaichkowsky (1985) considered several factors influencing consumer involvement, namely, personal, entity and situation, to develop a personal involvement inventory including twenty semantically different questions. The twenty questions were later simplified as ten questions with high validity and effectiveness, and the Zaichkowsky inventory is still widely used in academic studies today.

Ringberg, Schröder \& Christensen (2007) argue that this conflict results from the assumption that consumer recovery expectations are monolithic and largely homogeneous, driven mainly by behavioral, relational, or contextual stimuli. Instead, recovery scenarios involving high-involvement (i.e., self-relevant) goods and service failures may activate closely held, identity-related cultural models that, though ultimately applied to regain balance (a foundational schema), differ according to their sociocultural heritage and create a range of unique consumer recovery preferences.

Regarding high involvement, consumers consider something very important based on their own needs, values and interests. They then carefully evaluate the justice of resource distribution as well as of trade cognition. When service failure occurs, the money or goods returned to consumers by the company equals the value of the loss, i.e., the atonement the company gives to customers. Smith, Bolton \& Wagner (1999) also considered the effect of compensation on the perceived justice dimension of service recovery.

Such compensation is tangible, easily quantified and adequately explains the satisfaction with the recovery action. Additionally, the speed of high involvement (Smith, Bolton \& Wagner, 1999) is related to the empowerment of companies, which is the empowerment of service recovery. The following hypothesis is proposed:

Hypothesis 1-1: In high involvement consumers, compensation and the empowerment of service recovery positively affects perceived justice.

In low involvement consumers, users place less importance on something based on their own needs, values and interests. At this time, they may focus more on the interactive process of trading. For example, service personnel may consider it a reasonable method of gathering information, and also consider customer feelings in efforts to address service failures (Smith, Bolton \& Wagner, 1999; Tax, Brown \& 
Chandrashekaran, 1999). Therefore, perceived justice depends on the communication skills of service personnel, which are referred to as communication, feedback and explanation of service recovery. For instance, service personnel must OR should raise questions at the right time to clarify the situation and give neutral and objective feedback. Conversely, in low involvement, service personnel should stress such tangibles in dealing with failures, and customers should feel the sincerity of atonement, which is the tangible dimension of service recovery. We hypothesize the following:

Hypothesis 1-2: In low involvement consumers, communication, feedback, explanation and tangible service recovery compensation positively affect perceived justice.

Distributive justice refers to the justice of resource distribution and trade perception. High involvement consumers attach a greater importance to their own needs, values and interests. In brief, consumers use different amounts and types of information resources to increase perceived justice in accordance with the level and type of risk. Although the consumer decision-making model has demonstrated that information collection is an important factor in deciding what to buy, the literature reveals a critical gap, i.e., the relationship between different extents of involvement. For example, if the service recovery measures of a company enable its product or service to regain its original status, consumers with high demands for service, namely, high involvement consumers, feel higher distributive justice.

Hypothesis 1-3: In high involvement consumers, service recovery positively affects distributive justice.

Interactive justice refers to the outcome of information exchange and communication (Smith, Bolton \& Wagner, 1999; Tax, Brown \& Chandrashekaran, 1999). Low involvement consumers attach less importance to demands and focus more on the process of service. When a service failure occurs, consumers who do not receive a clear and well-communicated explanation tend to feel much stronger negative feelings. Therefore, in a service contact, if service personnel are able to control the quality of mutual treatment and communication, the negative feelings of consumers can be reduced, and interactive justice can be increased. The quality of mutual treatment and communication between people is interactive justice (Smith, Bolton \& Wagner, 1999). Based on this, in low involvement consumers, service recovery has a greater influence on interactive justice. The following hypothesis is proposed:

Hypothesis 1-4: In low involvement consumers, service recovery positively affects 
interactive justice.

\section{Subculture}

Culture has an important effect on consumer behavior because it provides consumers with a mechanism for perceiving and understanding acceptable social attitudes and behaviors (Engel, Blackwell \& Miniard, 1990). Culture can be defined as essentially a lifestyle that people share and pass on from generation to generation (Deblij, 1979). Such a definition suggests the universality of culture and indicates that it can be learned and can change over time.

People influenced by the same culture in a country share similar values. They grow up in the same society and have common consumption values. Even so, many differences are inevitable. In purchasing clothes, preferences will differ between a manager, a college student, a farmer and a factory worker. These differences may be considered subculture differences. People in the same subculture tend to possess similar consuming habits.

Subculture can also be defined as a social division differing from whole culture and is formed by independent values and behaviors (Peter \& Olson, 1987). Of course, subculture may affect the attitudes and behaviors of consumers, and thus, the importance of subculture in marketing and related studies is growing. Generally, subculture includes races, ages, areas and religions (Michael, 1999). A subculture may transcend trade barriers (Papadopoulos, 1992) and redefine groups traditionally defined by geographical boundaries. However, many marketing scholars adopt units of analysis defined by geographical area rather than national boundaries (e.g., Cox, 1995; Knox, 1996; Kolter, Haider \& Rein, 1993). Subculture initially influences consumer views of value, then lifestyles and finally consumer media behavior, shopping behavior and consuming behavior. Therefore, subculture affects the success of service recovery, particularly perceived justice.

Dunnett (2007) xamines the concept of organizational culture in the retailing context, particularly as it is cultivated and utilized within big box retailers to encourage and maintain a certain level of customer service among its employees. A stronger culture may be the equivalent of a more homogeneous culture, whereas a weaker culture may be more fragmented, comprising may subcultures. Brunetto \& Wharton (2006) compares the effectiveness of the administrative subculture of public and private sector employees by comparing the efficacy of their organizational processes. The paper provides some 
evidence that assumptions about the superiority of private sector administrative subculture (as measured by comparing the effectiveness of organizational communication processes in reducing task ambiguity) are probably not warranted.

In urban subculture, consumers pay more attention to their own rights and the service quality. If a company handling customer service inflexibly, customers are unable to know the schedule of processing the processing schedule will be unclear to consumers, who will then fail to express their opinions or feelings (Goodwin \& Ross, 1992). The condition is related to communication with and feedback from a company, i.e., the communication and feedback of service recovery. For example, when customers complain about poor service, it matters if the company writes to them and informs them of the problem solving process underway. Further, according to social exchange and equity theory, (Smith, et al., 1999), service failure is considered an exchange with service recovery, which includes information exchange. When customers are inadequately informed of the cause of a service failure (which also increases dissatisfaction with interaction) service personnel should consider giving customers a proper explanation and apology in hopes of reaching perception balance, which is the precise purpose of all service recovery action: customer empowerment. For example, customers usually feel upset when service personnel fail to provide a satisfactory explanation. In summary of the above, we hypothesize the following:

Hypothesis 2-1: In consumers in city subcultures, communication, feedback, explanation and empowerment of service recovery positively affect perceived justice.

In a subculture of a country, consumers pay more attention to final and concrete results. The biggest difference between service and products is that service is intangible. Invisible service requires visible clues before a customer can make a judgment (Zeithaml, 1988). Some examples would be the pleasant and professional appearance of staff and facilities. If service personnel stress the importance of visible appearance in dealing with service failure, customers are more likely to accept the sincerity of perceived atonement. Therefore, in the process of service failure and atonement, which also includes the tangible evidence of the exchange, namely, compensation and tangible service recovery, service personnel can project professionalism and sincerity when handling consumer complaints. The following hypothesize is proposed:

Hypothesis 2-2: In consumers within a subculture of a country, atonement and tangibility of service recovery positively affect perceived justice.

Processing justice refers to the decision making process and is necessary to solve 
conflicts (Smith, Bolton \& Wagner, 1999; Tax, Brown \& Chandrashekaran, 1999). Processing justice also denotes or refers to a process of dealing with service failure and whether that process is characterized by clear, transparent and complete information when taking service recovery action. In a city subculture, when service failure occurs, the level of processing justice will be lower if the policy and regulation of recovery procedure is unacceptable to consumers, is considered unfair by the peer groups of the consumers. The compensation process of service failure, additionally, may take consumers quite some time, and such a long period of time can irritate consumers, leading to further loss of time for consumers. The above mentioned policy and regulation of recovery process as well as the time spent by the consumer in question are termed processing justice (Smith, Bolton \& Wagner, 1999). Therefore, city subculture consumers stress the importance of efficiency, and service recovery has a higher influence on processing justice. The following hypothesis is proposed:

Hypothesis 2-3: Service recovery has a greater effect on processing justice in city subculture consumers.

Distributive justice refers to the outcome fairness of resource distribution and recognition of trading. When a service failure occurs, a company should compensate consumers with money or property equal to the loss suffered by the consumer. Smith, Bolton \& Wagner (1999) elucidated how distributive justice is affected by the compensation dimension of service recovery. Distributive justice is more concrete and easily quantified and can best be explained by satisfaction with recovery. Consumers within a country subculture pay more attention to the final result and visible aspects of a service recovery action. When service failure occurs, of all measures of service recovery, consumers care most about the fairness of the atonement results. Therefore, the fairness of distributive justice recovery is an important factor. The following hypothesis is proposed:

Hypothesis 2-4: For consumers in a country subculture, service recovery has a greater effect on distributive justice.

\section{VARIABLES AND MEASUREMENTS}

This study probed the causal relationship between service recovery and perceived justice. This study modifies the structure of previous studies of perceived justice by Tax et al. (1999) in order to clarify the interactive relationship between service recovery and perceived justice. The structure of this study is present as Figure 1. 
Research variables were measured on a six-point Likert scale. A range of responses from "very strongly disagree" to "very strongly agree" were represented on a scale of 1 to 6. Service recovery was measured by a modification of the RECOVSAT measure and a seventeen-item questionnaire measuring how interviewees felt about service recovery measures taken by the retailers. The measurement of perceived justice, which includes the three dimensions of processing justice, interactive justice and distributive justice is based on a measure developed by Maxham \& Netemeyer (2002), with some modification. This study used a six-point Likert scale to measure interviewee feelings regarding the perceived justice of a retailer after a customer service complaint. As for the involvement level, the ten semantically different questions of Zaichkowsky's (1994) personal involvement inventory; PII) are employed. Finally, subculture is further divided into city and country subculture, which is derived from the sample planning of questionnaire, where administration areas belonging to city level are called city subculture whereas areas belonging to country level country subculture.

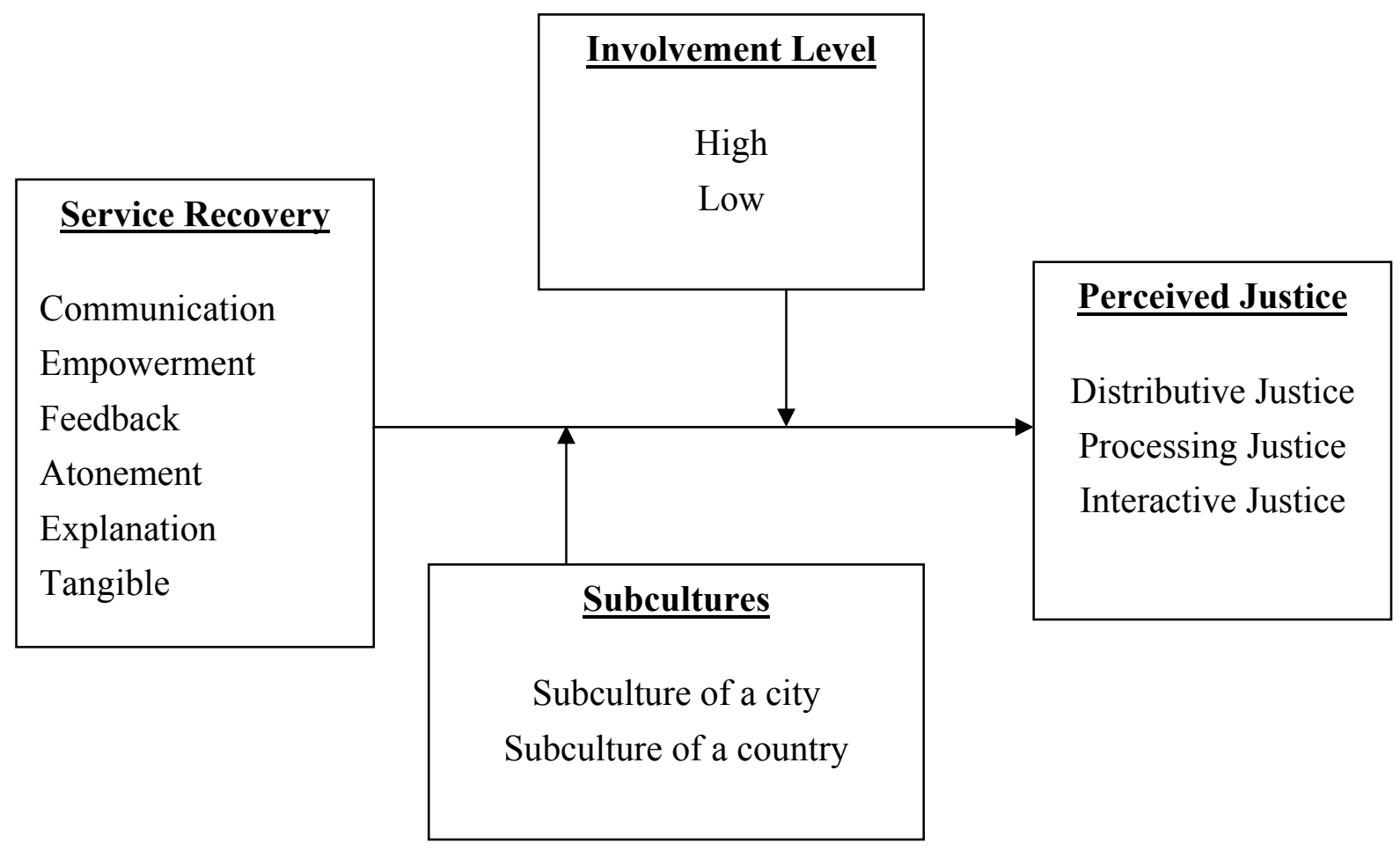

Figure 1 The Research Framework of The Study

Data collection was conducted in two stages. Sampling interviews were conducted in the pretest stage. The authors interviewed sample guests at reputable Taipei 
convenience stores at different times of day. Question items were modified based on the results of the pretest to improve validity. In the formal stage of the interview, ten trained interviewees visited 600 guests at twenty convenience stores in Taipei city and county. Research data was collected using the questionnaire. This effort yielded $78.83 \%$ useable surveys, an adequate sample for this study. The content of the questionnaire included four sections. The first section measured service recovery; the second section measured perceived justice; the third section measured involvement level, and the fourth section measured demographical variables (including gender, age, marital status, education, monthly income and profession).

\section{DATA ANALYSIS AND RESULTS}

Personal data and characteristics were divided into gender, age, marital status, occupation, education, and monthly income. In the study sample, the proportion of males and females was approximately equal. Age distribution was primarily 21-39 years old (63\%), and the majority of respondents were between 20 and 50 years old. Most respondents had a postsecondary education (50.3\%). Show the level of respondents' knowledge is analogous to competence, should possess remarkable understanding ability, the misunderstanding possibility to this research questionnaire content is relatively low too. Regarding employment, most respondents worked for private enterprises (49.3\%), which approximated actual employment statistics for Taipei released by the Republic of China in 2006, indicating a reasonably representative sample.

This study adopts the Cronbach alpha coefficient to weigh this consistency of reliability. Nunnally (1970) observed that if $\alpha$ coefficient is lower than 0.35 indicating the low reliability, the questionnaire should be considered invalid. Between 0.5 and 0.7 is acceptable, and exceeding 0.7 is considered high reliability. Guielford (1965) also suggested that reliability exceeding 0.7 is high, between 0.7 and 0.35 is acceptable and lower than 0.35 is unacceptable. With deleting items aspect, it precedes the correlation analysis of item to total to assay every question to its internal consistency of forming the variable. Churchill (1995) suggested deleting questions with a correlation coefficient lower than 0.50 . The alpha coefficients of all dimensions in this study were between 0.69 to 0.82 , which demonstrates their reliability. The correlation coefficient between each variable and its dimension exceeded 0.5 , indicating the question was valid.

The correlation coefficient between dimensions of service recovery ranged from 0.214 to 0.509 , which was higher than that between perceived justice and service 
recovery $(0.021$ to 0.236$)$. The correlation coefficient of perceived justice ranged from 0.656 to 0.743 , which was also higher than that between perceived justice and service recovery. The questionnaire showed good discriminative validity.

In order to explore whether there is any significant relationship between among variables, a recursive systems analysis was conducted as part of this study.

$$
\begin{aligned}
& Y_{b}=\beta_{0}+\beta_{1} Y_{a}+\varepsilon_{1} \\
& Y_{b}=\beta_{0}+\beta_{1} Y_{a}+\beta_{2} Y_{c}+\beta_{3} Y_{a} Y_{c}+\varepsilon_{2}
\end{aligned}
$$

Where $\mathrm{Y}$ is a vector of three variables, and $\mathrm{Y}_{\mathrm{a}}, \mathrm{Y}_{\mathrm{b}}, \mathrm{Y}_{\mathrm{c}}$ correspond to service recovery, perceived justice and involvement level, respectively. First, as equation-1 in table 1 indicates, this item had a statistically significant level, with the signs, as expected, being positive. This implies that the higher the service recovery, the higher the perception of justice. Therefore, forgoing hypothesis is supported. Further, the equation2 in table 1 indicates that there is the positive significant relationship between perceived justice and involvement level. In order to realize the modulation effect of involvement in this relationship, this study found t-value of the cross-item is significant, thereby being a quasi-modulated variable. In view of this, the effects of service recovery on perceived justice is affected by the modulation of involvement level. Hence, hypothesis 1 is supported.

To realize the influence of involvement level on service recovery and perceived justice in hypotheses 1-1 and 1-2, this study divided two types according to the high and low scores of involvement. As shown in table 2, involvement level has significant effects on perceived justice, and high involvement level has significant effects on the intersection of atonement and empowerment of service recovery. Reversely, low involvement level has significant effects on the intersection of communication, feedback, explanation and tangible of service recovery. This study shows that service recovery is helpful in increasing perceived justice. Despite its positive contribution, different involvement levels yield different effects. These findings support hypotheses 1-1 and 12. Furthermore, this study also divide samples into two groups in accordance with Taipei administration areas, of which the subjects sampled living in Taipei city and county belong to the same sample while the rest county areas another sample. To conduct a test for hypotheses 2-1 and 2-2, this study found that subculture has a significant effect on perceived justice. And the intersecting variable of city subculture and of the dimensions communication, feedback, explanation and empowerment of service recovery is significant. The intersecting variable of country subculture and the atonement and 
tangible of service recovery is significant. The above outcomes support hypotheses 2-1 and 2-2. Moreover, if the dependent variables are divided into three types (as shown in table 3), the three dimensions of perceived justice, the intersecting variable of high involvement level and service recovery is significant when the dependent variable is distributive justice; the intersecting variable of high involvement level and service recovery is not significant when the dependent variable is interactive justice. The above results support hypotheses 1-3 and 1-4. Finally, when the dependent variable is processing justice, the intersecting variable of city subculture and service recovery is significant; when the dependent variable is distributive justice, the intersecting variable of city subculture and service recovery is not significant. The above outcome support hypotheses 2-3 and 2-4.

Table 1 Results of Recursive Systems Models

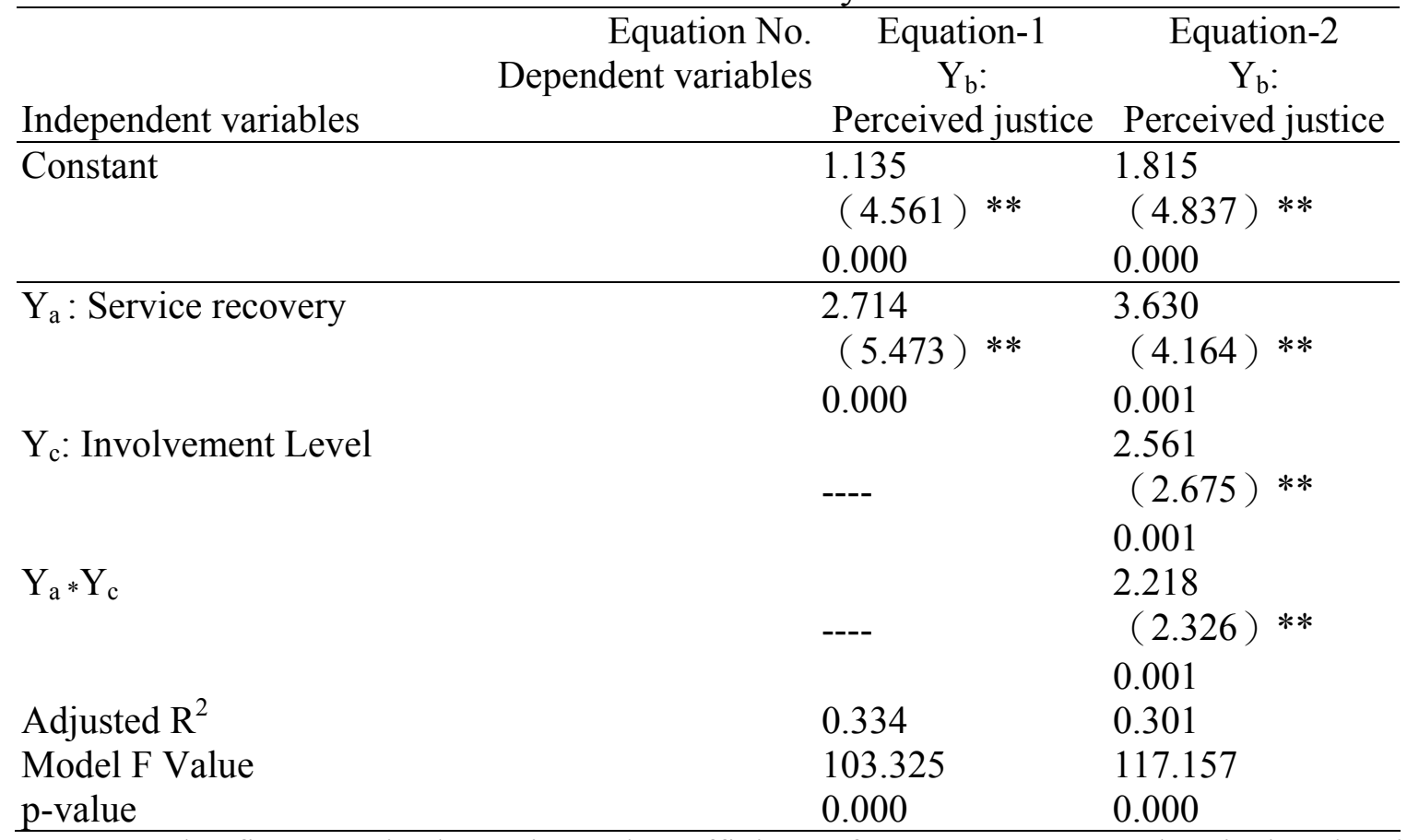

Notes: The first row is the estimated coefficient of parameters. Number in bracket is tvalue and the third row is the p-value. Based on one-tailed tests: for t-values greater than $1.65\left(^{*}\right), \mathrm{p}<0.05$; for $\mathrm{t}$-values greater than $2.33, \mathrm{p}<0.01(* *)$. 
Table 2 Results of Regressions of Six Dimensions of Service Recovery

\begin{tabular}{|c|c|c|c|}
\hline Ind or 1 & $\begin{array}{r}\text { Equation No. } \\
\text { Dependent variables }\end{array}$ & $\begin{array}{l}\text { Equation-1 } \\
\mathrm{Y}_{\mathrm{b}} \text { : }\end{array}$ & $\begin{array}{l}\text { Equation-2 } \\
\mathrm{Y}_{\mathrm{b}} \text { : }\end{array}$ \\
\hline Independent variables & & Perceived justice & Perceived justice \\
\hline \multirow{3}{*}{\multicolumn{2}{|c|}{ Constant }} & 2.461 & 2.531 \\
\hline & & $(2.651) * *$ & $(3.153) * *$ \\
\hline & & 0.001 & 0.001 \\
\hline \multirow{3}{*}{\multicolumn{2}{|c|}{$\mathrm{Y}_{\mathrm{a} 1}$ : Communication }} & 0.165 & 0.113 \\
\hline & & $(1.935) * *$ & $(1.137) * *$ \\
\hline & & 0.001 & 0.001 \\
\hline \multirow{3}{*}{\multicolumn{2}{|c|}{$\mathrm{Y}_{\mathrm{a} 2}$ : Feedback }} & 0.157 & 0.214 \\
\hline & & $(1.341) * *$ & $(1.225) * *$ \\
\hline & & 0.001 & 0.001 \\
\hline \multirow{3}{*}{\multicolumn{2}{|c|}{$\mathrm{Y}_{\mathrm{a} 3}$ : Explanation }} & 0.138 & 0.321 \\
\hline & & $(1.321) * *$ & $(1.212) * *$ \\
\hline & & 0.001 & 0.001 \\
\hline \multirow{3}{*}{\multicolumn{2}{|c|}{$\mathrm{Y}_{\mathrm{a} 4}:$ Empowerment }} & 0.195 & 0.179 \\
\hline & & $(1.121) * *$ & $(1.981) * *$ \\
\hline & & 0.001 & 0.001 \\
\hline \multirow{3}{*}{\multicolumn{2}{|c|}{$\mathrm{Y}_{\mathrm{a} 5}$ : Atonement }} & 0.218 & 0.194 \\
\hline & & $(2.151) * *$ & $(1.838) * *$ \\
\hline & & 0.001 & 0.001 \\
\hline \multirow{3}{*}{$\mathrm{Y}_{\mathrm{a} 6}$ : Tangible } & & 0.115 & 0.118 \\
\hline & & $(1.321) * *$ & $(1.713) * *$ \\
\hline & & 0.001 & 0.001 \\
\hline \multirow{3}{*}{$\begin{array}{l}\mathrm{Y}_{\mathrm{c} 1} \text { :Involvement Level } \\
\quad(\mathrm{High}=1, \text { Low }=0)\end{array}$} & & 0.215 & \\
\hline & & $(1.354) * *$ & ---- \\
\hline & & 0.001 & \\
\hline \multirow{2}{*}{$\begin{array}{l}Y_{\mathrm{c} 2}: \text { Subculture } \\
\quad(\text { City }=1, \text { Country }=0)\end{array}$} & & & 1.185 \\
\hline & & ---- & $\begin{array}{c}(2.846) \\
0.001\end{array}$ \\
\hline \multirow[t]{3}{*}{$\mathrm{Y}_{\mathrm{a} 4 * \mathrm{Y}_{\mathrm{c} 1}}$} & & 0.014 & \\
\hline & & $(0.894) *$ & ---- \\
\hline & & 0.021 & \\
\hline \multirow[t]{3}{*}{$\mathrm{Y}_{\mathrm{a} 5} * \mathrm{Y}_{\mathrm{c} 1}$} & & 0.021 & \\
\hline & & $(0.931) *$ & ---- \\
\hline & & 0.031 & \\
\hline \multirow[t]{3}{*}{$Y_{a 1 *} Y_{c 2}$} & & & 1.152 \\
\hline & & ---- & $(1.128) * *$ \\
\hline & & & 0.005 \\
\hline
\end{tabular}


Table 2 Results of Regressions of Six Dimensions of Service Recovery (Continued)

\begin{tabular}{|c|c|c|c|}
\hline $\begin{array}{l}\text { Independent variables } \\
\mathrm{Y}_{\mathrm{a} 2} * \mathrm{Y}_{\mathrm{c} 2}\end{array}$ & $\begin{array}{r}\text { Equation No. } \\
\text { Dependent variables }\end{array}$ & $\begin{array}{c}\text { Equation-1 } \\
\text { Yb: } \\
\text { Perceived justice }\end{array}$ & $\begin{array}{c}\text { Equation-2 } \\
\text { Yb: } \\
\text { Perceived justice } \\
1.031\end{array}$ \\
\hline & & --- & $(1.101) * *$ \\
\hline$Y_{\mathrm{a} 3} * Y_{\mathrm{c} 2}$ & & & $\begin{array}{l}0.105 \\
1.037\end{array}$ \\
\hline & & ---- & $\begin{array}{l}(1.002) * * \\
0.125\end{array}$ \\
\hline $\mathrm{Y}_{\mathrm{a} 4} * \mathrm{Y}_{\mathrm{c} 2}$ & & ---- & $\begin{array}{c}1.037 \\
(1.022) * * \\
0.005\end{array}$ \\
\hline
\end{tabular}

Notes: The first row is the estimated coefficient of parameters. Number in bracket is $\mathrm{t}$-value and the third row is the p-value. Based on one-tailed tests: for $\mathrm{t}$ values greater than $1.65(*), \mathrm{p}<0.05$; for $\mathrm{t}$-values greater than 2.33, $\mathrm{p}<0.01(* *)$.

Table 3 Results of Regressions of Three Dimensions of Perceived Justice

$$
\text { Equation No. } \quad \text { Equation-1 } \quad \text { Equation-2 } \quad \text { Equation-3 }
$$

Dependent variables $\quad \mathrm{Y}_{\mathrm{b} 1}$ : $\quad \mathrm{Y}_{\mathrm{b} 2}$ : $\quad \mathrm{Y}_{\mathrm{b} 3}$ :

Independent variables Distributive Justice Processing Justice Interactive Justice

\begin{tabular}{lccc}
\hline Constant & 1.135 & 3.631 & 2.315 \\
& $(1.155)^{* *}$ & $(5.924)^{* *}$ & $(3.842)^{* *}$ \\
& 0.001 & 0.000 & 0.001 \\
\hline $\mathrm{Y}_{\mathrm{a}}:$ Service recovery & 0.125 & 0.138 & 0.187 \\
& $(1.311)^{* *}$ & $(1.215)^{* *}$ & $(1.984)^{* *}$ \\
& 0.001 & 0.001 & 0.001 \\
\hline $\mathrm{Y}_{\mathrm{c} 1}$ :Involvement Level & & & \\
$\quad($ High =1, Low $=0)$ & ---- & --- & --- \\
$\mathrm{Y}_{\mathrm{c} 2}:$ Subculture & & --- & ---- \\
$($ City=1, Country=0) & ---- & --- & 1.315 \\
$\mathrm{Y}_{\mathrm{a}^{*}} \mathrm{Y}_{\mathrm{c} 1}$ & 1.015 & 0.214 & $(2.218)^{* *}$ \\
& $(2.117)^{* *}$ & $(0.018)$ & 0.001 \\
$\mathrm{Y}_{\mathrm{a}^{*}} \mathrm{Y}_{\mathrm{c} 2}$ & 0.001 & 0.501 & - \\
& 0.131 & & -- \\
\hline
\end{tabular}

Notes: The first row is the estimated coefficient of parameters. Number in bracket is tvalue and the third row is the $\mathrm{p}$-value. Based on one-tailed tests: for t-values greater than $1.65(*), \mathrm{p}<0.05$; for $\mathrm{t}$-values greater than $2.33, \mathrm{p}<0.01(* *)$. 


\section{CONCLUSION}

This study aims to elucidate the relationship between service recovery and perceived justice. After a service failure, service recovery is the main cause of customer brand switching behavior, and may instill a more positive or negative consumer attitude toward the company. Recently, the entire economic environment in Taiwan has been inhospitable. The impact on service industry is worse than ever. Retail industries have attempted various promotion strategies and activities to attract consumers and stabilize their businesses. However, if service failures can be dealt with appropriately, long-term customer relationships are likely to form (Webster \& Sundaram, 1998). Furthermore, proper handling of service failures not only satisfies customers but helps to build a longterm relationship (Westbrook, 1987). In terms of different levels of involvement and subculture, the value of implementing service recovery is higher than before. Therefore, exploring the cause and effect of the variables in these theories has numerous practical implications. The contribution of our studies is the application of low modulation variables, namely, involvement and subculture, to explore the above cause-effect relationship. Exploring the growing importance of perceived justice in the retail industry can enhance understanding of compensation satisfaction.

One aspect of our studies is service recovery strategies. When service failure occurs, proper service recovery can raise the perceived justice of consumers. Our studies further explore the relationship between service recovery and customer satisfaction. We find that service recovery in the retail industry can increase customer perceived justice. Application of our proposed service recovery strategies, such as proper explanation and communication, can increase perceived justice as well as customer satisfaction.

This study also considered the hypothesis of modulating variables, i.e., testing an independent variable (service recovery), modulated variables (involvement, subculture) and an explained variable (perceived justice). After repeated recursive analysis and general recursive modulating variables, the coefficient of multiplication variables between involvement level and perceived justice was revealed, which is consistent with our findings regarding relation modulation. The results are as follows: in high involvement consumers, atonement and empowerment of service recovery have a greater effect on perceived justice; in low involvement consumers, the communication, feedback, explanation and tangibility of service recovery have a greater effect on perceived justice. As for city subculture, the communication, feedback, explanation and empowerment of

service recovery have greater effects on perceived justice. Under country subculture, the 
atonement and tangibility of service recovery have a greater influence on perceived justice. Finally, in terms of the three dimensions of perceived justice, we find that in high involvement consumers, service recovery significantly affects distributive justice. Conversely, in low involvement consumers, service recovery influences interactive justice. In a city subculture, service recovery has a greater effect on processing justice; in a country subculture, service recovery has a higher impact on distributive justice. Restated, when customers are faced with service failure, the service recovery measures of a company increase perceived justice. Customers thus feel the company is fairly dealing with the failure, which in turn changes customer attitudes towards the company. Such a change influences the level of customer involvement and subculture. For example, in high involvement consumers belonging to a city subculture, compensation measures of distributive and processing justice, such as atonement and empowerment, can be increased, thus increasing customer satisfaction. Therefore, if the related information about customers, which means being unable to understand the level of involvement and subculture of customers, the compensation measures taken tend to lose their effects.

Moreover, our findings compare favorably with previous studies elsewhere. For example, in an analysis of service atonement in medical organization, Kenney (1995) observed that service recovery is the action taken by an organization to smooth the dissatisfied feelings of customers who are upset with the service. At the same time, service recovery is a good chance to regain customer satisfaction. Kennedy divided service recovery into two dimensions: 1. Customer dissatisfaction reduced by apology and explanation. 2. Customer loss compensated by substantial atonement. The studies of Christo (1997) analyzed airline passengers to explore the effects of different service recovery approaches on customer satisfaction. His studies focused on visible atonement, which was divided into three aspects: apology, apology plus atonement and apology with overcompensated atonement. Christo found that visible atonement has a certain effect on customer satisfaction, but is not the only necessary requirement; response time to complaints was found to be inversely proportional to customer satisfaction. The inverse relationship is more pronounced when customer must wait longer for compensation. Our studies further indicate that involvement level and subculture are critical for increasing customer perceived justice. Restated, in addition to positive atonement, the most important response is to demonstrate to the customer that the complaint is clearly understood. In view of this, our studies extend the analyses of studies cited above.

With increasing awareness of consumer rights, consumers are more apt to complain 
when faced with service failure or dissatisfaction. Therefore, a company failing to effectively address a service failure is likely to lose not only current customers, but potential future customers as well through negative publicity or loss of business reputation.

According to previous studies, different types of service failure can be compensated for in different ways to minimize customer dissatisfaction. Our studies further elucidate the modulating effects of involvement level and subculture, which means subjects of service recovery, can be classified by involvement level and subculture. Proper atonement measures can be adopted to increase perceived justice.

Therefore, companies are advised to adopt service failure atonement subject separation to confirm compensation chances so that customer needs can be met. Appropriate compensation strategies can be modified for different target markets. For instance, in a city retail industry with a higher city subculture, service recovery in the retail industry can reinforce the social image and quality of a retailer, which indirectly increases perceived processing justice and in turn increases customer satisfaction. Clearly, failure is unavoidable. However, by accurate classification of service recovery subjects, consumers will experience fair distribution, processing and interaction all of which increase their willingness to consume.

The outcome of our studies may have some limitations requiring further elucidation. We suggest the following further studies. In terms of framework, we base our studies on related literature, most of which does not adequately address variable relationships. Because of the current immaturity of components and classification, future studies may elucidate the various dimensions influencing the formation of perceived justice. In terms of methods and data collection, our studies targeted convenience stores in Taipei city and county. Geographical areas and interviewee ages were randomly sampled and did not include different types of retail businesses. Such a sampling can be improved in future studies so that the data sampled can more accurately represent the subjects of our studies.

\section{ACKNOWLEDGEMENT}

The authors would like to thank the National Science Council of the Republic of China for financially supporting this research under Contract No. NSC 94-2416-H-237003 . 


\section{REFERENCES}

Bitner, M. J., Boom, B. M., \& Tetreault, M. S. (1990). The service encounter: Diagnosing favorable and unfavorable incidents. Journal of Marketing, 54(1), 71-85.

Bitner, M. J., Booms, B. H., \& Mohr, L. A. (1994). Critical service encounters: The employee's viewpoint. Journal of Marketing, 58(4), 95-106.

Bloch P. H., \& Richins, M. L. (1983). A theoretical model for the study of product importance perceptions. Journal of Marketing, 47(2), 3-11.

Boshoff, C. (1999). Recover: An instrument to measure satisfaction with transactionspecific service recovery. Journal of Service Research, 1(3), 236-249.

Boulding. W, A. Kalra \& V. A. Zeithaml (1993). A dynamic process model of service quality: From expectations to behavioral intentions. Journal of Marketing Research, $30(1), 7-27$.

Bowen, D. E., \& Lawler III, E. E. (1995). Empowering service employees. Sloan Management Review, 36, 73-84.

Brunetto Yvonne \& Rod Farr Wharton. (2006). Comparison of the Administrative Subculture of Public and Private Sector Service Employees. International Journal of Public Administration. New York, 29(8), 11-23.

Chebat, Jean-Charles \& Witold Slusarczyk. (2005). How emotions mediate the effects of perceived justice on loyalty in service recovery situations: an empirical study. Journal of Business Research. 58(5), 664-675.

Christo, B. (1997). An experimental study of service recovery option. International Journal of Service Industry Management, 8(14), 110-130.

Churchill, G. A. \& Peter, J. P. (1998). Marketing: Creating Value for Customers, (2nd Ed.), Chicogo, McGraw Hill.

Churchill, G. A. Jr. (1995). Marketing Research: Methodological Foundations, 6th ed., NY: The Dryden Press.

Clemmer, Elizabeth C. \& Schneider\&cedil; Benjamin (1996). Fair Service in Advances in Services Marketing and Management. Vol. 5, Teresa A. Swartz, David E. Bowen and Stephen W. Brown, eds. Greenwich, CT: JAI Press,109-26.

Cox, K. R. (1995). Globalisation, Competition and the Politics of Local Economic Development. Urban Studies, 32(2), 213-224.

Deblij, Katherine Ruth (1979). Judgments of Dangerousness, Deviance, Mental Illness, and Necessity Of Hospitalization as a Function of Sex of Rater, Sex of Accused, Diagnostic Label and Type of Psychopathology, Ph.D., University of Miami, 149 
pages.

Dunnett, A Jane. (2007). The Role of Organizational Culture in Customer Service. The Business Review, Cambridge. 7(1), 38-44.

Engel J. F., Blackwell R. D. \& Miniard P. W. (1990). Consumer Behavior. New York: Dryden Press.

Fisk, R. P., Brown, S. W., \& Bitner, M. J. (1995). Tracking the evolution of the service marketing literature. Journal of Retailing, 69 (1), 61-103.

Goodwin, Cathy \& Ivan Ross (1992). Consumer Responses to Service Failures: Influence of Procedural and Interactional Fairness Perceptions. Journal of Business Research, 25 (September), 149-163.

Gronroos, C. (1988). Service quality: The six criteria of good perceive service quality. Review of Business, 9(4), 10-13.

Guielford, J.P. (1965). Fundamental Statistics in Psychology and Education. 4th ed., New York: McGraw-Hill.

Hart, C. W. L., Heskett, J. L. \& Sasser, W. (1990). The profitable art of service recovery. Harvard Business Review, 68(4), 148-156.

Hoffman, K. D., S. W. Kelley \& H. M. Rotalsky (1995). Tracking Service Failures and Employee Recovery Efforts. Journal of Service Marketing, 9(2): 49-61.

Hoffman, K. Douglas \& Scott W. Kelley. (2000). Perceived justice needs and recovery evaluation: a contingency approach. European Journal of Marketing. 34(3), 418-425.

Kau, Ah-Keng \& Elizabeth W.Y. Loh. (2006). The effects of service recovery on consumer satisfaction: a comparison between complainants and noncomplainants. The Journal of Services Marketing, 20(2), 101-18.

Kelley, S. W., Hoffman, K. D., \& Davis, M. A. (1993). A typology of retail failures and recoveries. Journal of Retailing, 69(4), 429-452.

Kenney, M. J. (1995). Antecedents to Customer Expectations for Service Recovery. Journal of Academy of Marketing Science, 22(1), 52-62.

Knox, P. L. (1996). Globalization and Urban Change. Urban Geography, 17(1), 115-117. Kotler, P., Haider, D.H., \& Rein, I. (1993). Marketing Places., New York, NY: Free Press.

Krugman, H. E. (1965). The Impact of Television Advertising; Learning without Involvement. Public Option Quarterly, 29(Fall), 349-356.

Lapidus, R. S., \& Pinkerton, L. (1995). Customer complaint situations: A equity theory. Psychology and Marketing, 12(2), 105- 122. 
Liao, Hui (2007). Do It Right This Time: The Role of Employee Service Recovery Performance in Customer-Perceived Justice and Customer Loyalty After Service Failures. Journal of Applied Psychology. 92(2), 475-87.

Maxham III, James G \&, Richard G Netemeyer (2002). Modeling customer perceptions of complaint handling over time: The effects of perceived justice on satisfaction and intent. Journal of Retailing. 78(4); 239-245.

Michael R. S. (1999). Consumer Behavior. Fourth Ed. NJ: Prentice Hall International Inc.

Nunnally, J. C. (1970). Introduction to Psychological Measurement, New York: McGraw-Hill.

Oliver, Richard L. \& John E. Swan (1989). Consumer Perceptions of International Equity and Satisfaction in Transactions: A Field Survey Approach. Journal of Marketing, 53, 21-35.

Papadopoulos, N. (1992). Trade Blocs and Marketing: Antecedents, Trends, and Implications. Journal of Global Marketing, 5(3): 1-29.

Peter, P., \& Olson, J. (1987). Consumer Behavior. Homewood, IL: Irwin.

Ringberg, Torsten, Gaby Odekerken Schröder \& Glenn L. Christensen. (2007). A Cultural Models Approach to Service Recovery. Journal of Marketing. 71(3), 194205.

Schoefer, Klaus \& Christine Ennew. (2005). The impact of perceived justice on consumers' emotional responses to service complaint experiences. The Journal of Services Marketing. 19(5), 261-270.

Smith, A.K., Bolton, R.N., \& Wagner, J. (1999). A model of customer satisfaction with service encounters involving failure and recovery. Journal of Marketing Research, 356-372.

Tax, S. S., \& Brown, S. W. (1998). Recovering and learning from ser-vice failure. Sloan Management Review, 55(4), 75-88.

Tax, S. S., W. B. Brown, \& M. Chandrashekaran, (1999). Customer Evaluations of Service Complaint Experiences: Implications for Relationship Marketing. Journal of Marketing, 62(4), 60-77.

Webster, C., \& Sundaram, D. S. (1998). Service consumption criticality in failure recovery. Journal of Business Research, 41(2), 153-159.

Westbrook, R. A. (1987). Product/consumption-based affective re-sponses and postpurchase processes. Journal of Marketing Research, 24(8), 258-270.

Yim, Chi Kin , Flora Fang Gu, Kimmy Wa Chan \& David K Tse. (2003). Justice-based 
service recovery expectations: measurement and antecedents. Journal of Consumer Satisfaction, Dissatisfaction and Complaining Behavior. 16,(1) 36-52.

Zaichkowsky, J. L. (1985). Measuring the involvement construct. Journal of Consumer Research, 12(12), 341-352.

Zaichkowsky, J. L. (1994). The Personal Involvement Inventory: Reduction, and Application to Advertising. Journal of Advertising, 23(1), 59-70.

Zeithaml, V. A. (1988). Consumer Perceptions of Price, Quality, and Value: A MeansEnd Model and Synthesis of Evidence. Journal of Marketing, 52(1), 2-21. 